\title{
Pattern of Prostate Specific Antigen and Gleason Score in Relation to Imunohistochemistry Features in Prostate Adenocarcinoma Patients in Dr. Hasan Sadikin General Hospital
}

\author{
Azela Glady, ${ }^{1}$ Endah Hamidah, ${ }^{1}$ Rahmat Budi Prasetyo, ${ }^{1}$ Agung Budi Sutiono ${ }^{2}$ \\ ${ }^{1}$ Faculty of Medicine, University of Jenderal Achmad Yani \\ ${ }^{2}$ Department of Neurosurgery, Faculty of Medicine, Universitas Padjadjaran-Dr. Hasan Sadikin General Hospital
}

\begin{abstract}
Objective: To review the correlation between prostate specific antigen (PSA) and Gleason score and Cav-1 for diagnosing prostate adenocarcinoma.

Methods: Data were collected from one hundred fifty-nine patients with prostate adenocarcinoma at the Department of Urology, Dr. Hasan Sadikin General Hospital in the period of January 2008-December 2010. The PSA levels were measured and classified into $<4 \mathrm{ng} / \mathrm{ml}, 4-10 \mathrm{ng} / \mathrm{ml}$, and $>10 \mathrm{ng} /$ $\mathrm{ml}$. The results were then analyzed and compared to the imunohistochemistry (caveolin-1) staining in the literature. The Gleason score was also noted and analyzed.

Results: This study confirmed that positive caveolin-1 expression was related to the clinical markers of disease progression and was predictive of poor clinical outcome after surgery. The PSA results showed that one hundred fourty-one adenocarcinoma patients had a PSA level of $>10 \mathrm{ng} / \mathrm{ml}$ with Gleason score of gleason 5-6 as the most common score. However, there was no correlation between PSA and Gleason score and caveolin-1 for diagnosing prostate adenocarcinoma.
\end{abstract}

Received:

Conclusions: Caveolin-1 cannot be used to measure Gleason and PSA score

July 9, 2015 due to different markers that have various advantages and disadvantages to predict carcinoma prostate. Therefore, further studies are needed.

Revised:

December 17, 2015

Keywords: Gleason score, imunohistochemistry, prostate adenocarcinoma, prostate specific antigen

Accepted:

February 26, 2016

IJIHS. 2016;4(1):1-7

\section{Introduction}

Prostate adenocarcinoma is the malignancy that is most frequently found and also the second most common cause of death in men. ${ }^{1,2}$ Adenocarcinoma of the prostate generally occurs at the age of $>50$ years but does not generate any clinical symptoms. Hence, most patients come at advanced stages. About $20 \%$ of the prostate adenocarcinoma is found incidentally in a histopatological procedure for examining the prostate gland based on the indication of hyperplasia. ${ }^{3}$

Adenocarcinoma prostate showed a high morbidity and mortality with a number of

Correspondence:

Azela Glady, Faculty of Medicine, Universitas Jenderal Achmad Yani

Jl. Jenderal Sudirman, Cimahi, Indonesia e-mail: gladyazela@gmail.com
234.460 diagnosed and 27.350 passed away after diagnosed. ${ }^{4}$ A study found more than 230.000 new cases and 30.000 of them was death. $^{5}$

Many ways were conducted to diagnose adenocarcinoma in its early stage, one of the strategy is by measuring the prostate specific antigen (PSA) level. ${ }^{6,7}$ Prostate specific antigen is a glicoprotein produced by the prostate gland with a normal level $<4 \mathrm{ng} / \mathrm{ml}$. A number of studies showed that PSA can be used to diagnose adenocarcinoma prostate with $75 \%$ accuration. ${ }^{8,9}$

Biopsy and histopatology are alternative ways to diagnose adenocarcinoma prostate. The Gleasson score can be used to determine when the histopatology analysis was carried out. The Gleasson score is an indication for the malignancy of adenocarcinoma prostate and important for a prognosis. The Gleason 
score indicates prostate cancer based on its microscopic appearance. Thus, the higher the Gleasson score means it is more malignant but with poor prognosis. The five basic grade patterns are used to generate a histologic score and measure the Gleason score, which can be ranged from 2 to 10 , by adding the primary and the secondary grade patterns. The primary pattern is the one that is predominant in the area, by a simple visual inspection. The secondary pattern is the second most common pattern. If only one grade is in the tissue sample, that grade is multiplied by two to give a score. According to the Gleason approach of 1977 , if the second grade is less than $3 \%$ of the total tumor, it is ignored, and the primary grade is again doubled to give the Gleason score (Fig. 1). , $^{50-14}$

Furthermore, a previous study identified and characterized clearly the overexpression of caveolin-1 (cav-1) gene occurring in a mouse model of prostate carcinoma and a human prostate carcinoma. In several clinical cases which determined the localization of prostate carcinoma showed cav-1 expression is a novel prognostic marker with independent predictive value of biochemical recurrence. ${ }^{12}$ Adenocarcinoma is one of the major problems found in male aged above 50 years. Therefore, an early detection is very usefull to reduce morbidity for adenocarcinoma prostate.

\section{Methods}

One hundred fifty-nine data of patients were taken from medical records with inclusion criterion, patients who were diagnosed with adenocarcinoma in the period 20112012 in Dr. Hasan Sadikin General Hospital, Bandung with symptoms of nocturia, urgency, retention urine and risk factor $>50$ years old.

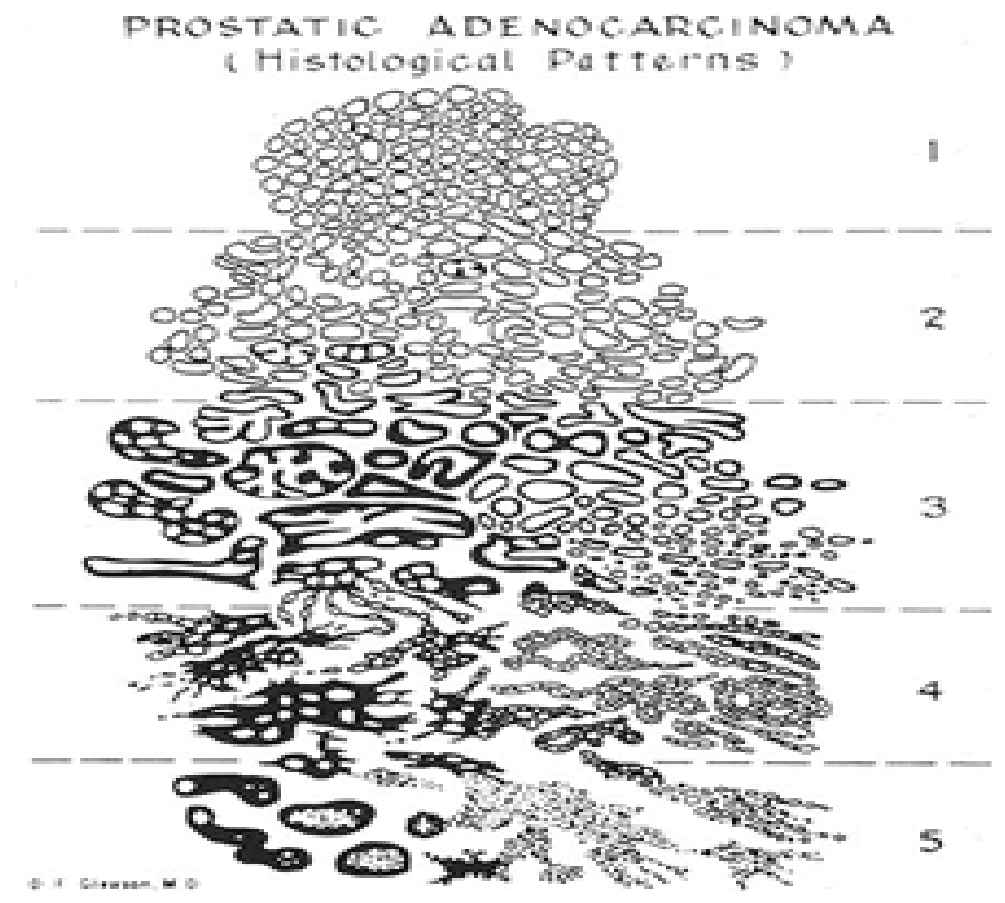

Fig. 1 Gleason Score from Lower to Higher. ${ }^{1}$ Gleason Pattern 1: Circumscribed Nodule of Closely Packed Uniform Glands, Gleason Pattern 2: Circumscribed Nodule of Loosely Packed Slightly Variable Glands, Gleason Pattern 3: Single Glands of Variable Size and Density, with an Infiltrative Pattern, Each Separated by at Least a Strand of Stroma, Gleason Pattern 4: Ragged Infiltration with Poorly Formed Glands or Sheets and Cords of Fused Glands, Poorly Formed Glands Includes Small Nests of Cells with only a Rudimentary Formed Lumenal Space (almost Rosette Like), Gleason Pattern 5: Ragged Infiltrative Single cells, Cords or Sheets, Granular 
They performed rectal tussae examination, measured the PSA level and histopathology to obtain the Gleason score. The prostate specific antigen level was measured and classified into $<4 \mathrm{ng} / \mathrm{ml}, 4-10 \mathrm{ng} / \mathrm{ml},>10 \mathrm{ng} / \mathrm{ml}$. Those results were analyzed and compared into the imunohistochemistry (caveolin-1) of staining in the literature. The Gleason score was also noted (Fig 2).

\section{Results}

This study found that out of 156 patients, most of adenocarcinoma prostate patients occured in male who were $>50$ years old, with the highest incidence rate occuring in 75 patients aged 61-70 years (Fig. 3).

Additionally, the prostate specific antigen level was classified into $<4 \mathrm{ng} / \mathrm{mL}$ usually normal in male, $4-10 \mathrm{ng} / \mathrm{mL}$ which is called the grey area, and $>10 \mathrm{ng} / \mathrm{mL}$ which strongly indicates carcinoma. Apparently, one hundred fourty-one adenocarcinoma patients had PSA level >10 ng/ml (Fig. 4). Moreover, the Gleason score is classified into Gleason 2-4 which means good differentiated, Gleason 5-6 means moderate differentiated, Gleason 7-10 means poorly differentiated, and eighty patients had Gleason score 5-6 (Fig. 5).

Cav-1 immunoreactivity was detected in the cytoplasm of tumor cells in a granular pattern after comparing with immunohistochemistry from literature. The validity of the staining reactions was confirmed by the strong staining reactions characteristic of smooth muscle and endothelial cells within the stroma, although the proportion of cav-1-positive tumor cells were varied within individual specimens. Furthermore, cav-1 reactivity was not detected in histologically normal epithelial cells in areas adjacent to the tumor. The patient group with a PSA level $>10 \mathrm{ng} / \mathrm{mL}$ was found to have the highest rate of cav-1-positive tumors. However, no significant correlation between cav-1 expression and preoperative serum PSA level was found $(\mathrm{p}=0.203$, Spearman correlation test) and there was a tendency toward a higher incidence of cav-1 expression with a higher Gleason score, and no significant correlation between cav-1 expression and Gleason score was found $(\mathrm{p}=0.100$; Spearman

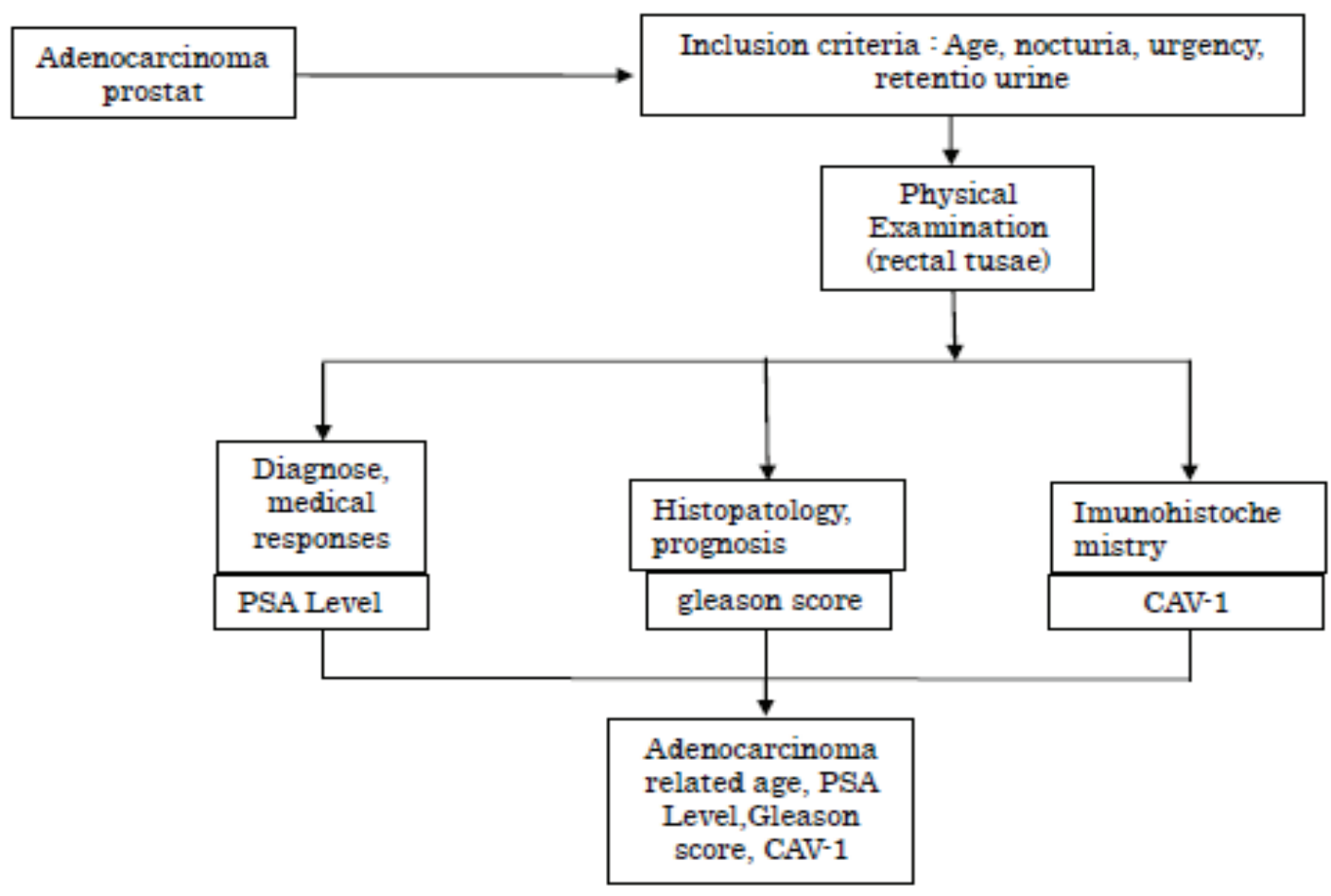

Fig. 2 Research Framework 


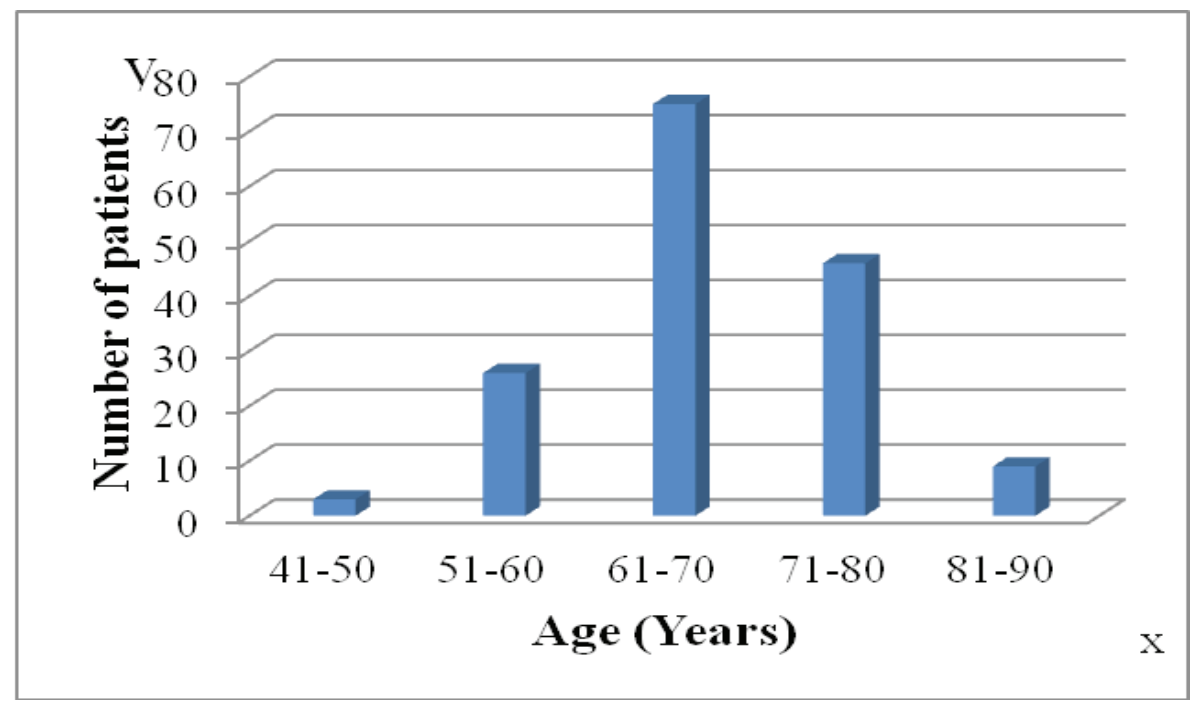

Fig. 3 Age Distribution

correlation test). The description of Caveolin-1 immunostaining in moderately differentiated prostate carcinoma cases and Caveolin-1 expression as demonstrated by avidin-biotin complex immunohistochemical staining in moderately differentiated prostate carcinoma cases are shown (Fig. 6). ${ }^{20}$

\section{Discussion}

Adenocarcinoma prostate generally occurs at the age of $>50$ years but does not generate any clinical symptoms. In the result, it showed that most of the patients with adenocarcinoma prostate are between 61-70 years old. The results have similarity with a previous study in dr. Moewardi Surakarta Hospital, the most common patients were aged $65-75$ years. ${ }^{13}$ Furthermore, another study in Barbados also revealed the most common age was between 65-75 years old. ${ }^{14}$ This is similar to the theory that adenocarcinoma is related with age and usually occurs at the age $>50$ years old.

The serum PSA screening has led to a dramatic increase in the diagnosis of prostate

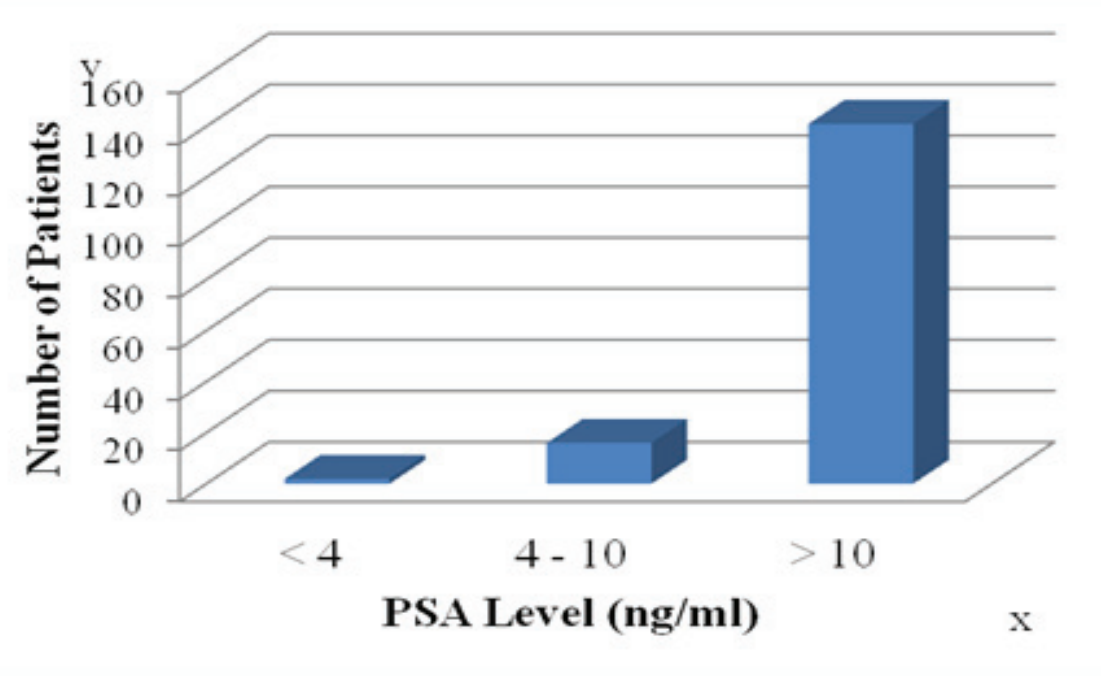

Fig. 4 Adenocarcinoma Prostat Correlation with PSA Level 


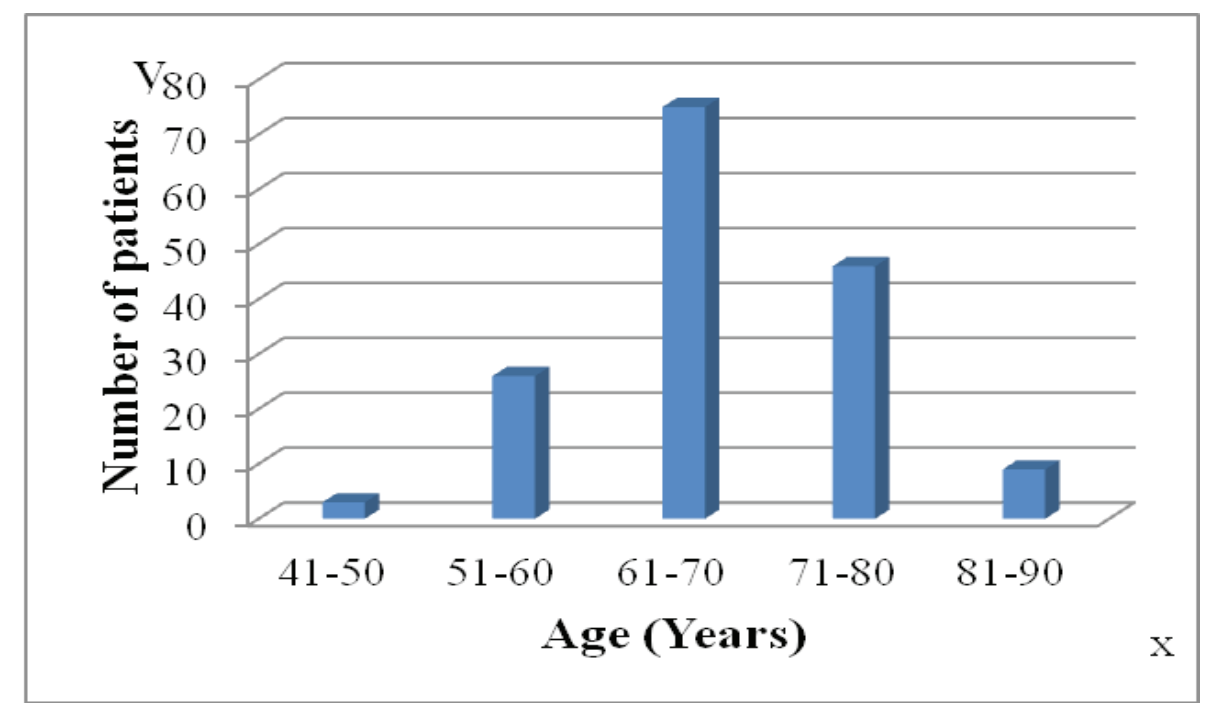

Fig. 5 Adenocarcinoma Prostat Correlation with Gleason Score

carcinoma as well as in the number of male undergoing radical prostatectomy in the past decade. ${ }^{15,16}$ In the United States, the number of newly diagnosed prostate carcinoma cases and cancer specific mortality appear to be declining; inspite of this, it is unclear whether these reductions are related to increased screening and earlier aggressive treatment, misclassification of cause of death, or more complex population dynamics. ${ }^{17}$ This PSA study showed similarity with a study from dr. Kariadi Semarang from 2000-2006 which found PSA $>10 \mathrm{ng} / \mathrm{mL}$ in an adenocarcinoma patient. Thus, the finding in this study is similar to the previous study. The increase in serum PSA observed in prostate cancer patients is not due to increased expression of PSA on a cellular level. However, it is rather a tumor-associated disruption of the normal prostate tissue architecture that leads to the increased release of PSA into peripheral blood. Prostate specific antigen was first approved in 1986 by the Food and Drug Administration (FDA) to monitor response in patients treated for prostate cancer and subsequently as a diagnostic marker in 1994. Even at the time of its discovery, however, three inherent limitations of PSA as a biomarker were evident.

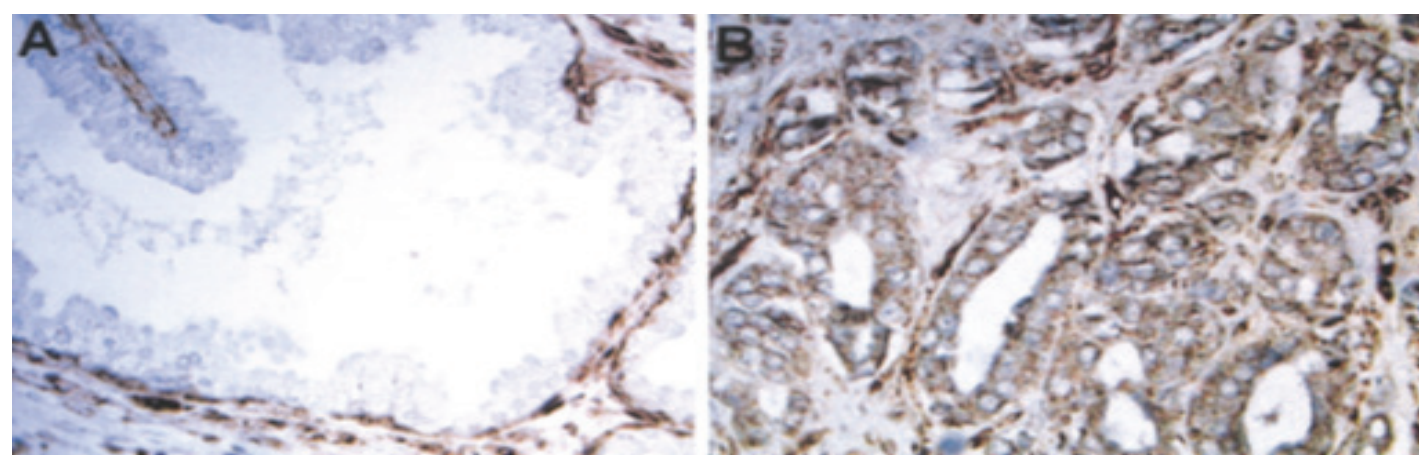

Fig. 6 Cav-1 in normal prostate was localized primarily to smooth muscle cells and endothelial cells in the stroma with negatively stained glandular epithelia (a). In contrast, cav-1 immunostaining was present in the cytoplasm of tumor cells (b) ${ }^{20}$ 
First, PSA is not regarded a prostate cancer specific antigen. Second, PSA does not reliably predict the grade or stage of prostate cancer at diagnosis. Third, PSA reflects tumor volume, however does not functionally contribute to the patophysiology of the tumor progression. Therefore, PSA does not distinguish clinically significance from insignificant prostate cancer. For these reasons, the PSA is most useful as a prognostic tool when combined with other clinicopathologic parameters. ${ }^{18}$

The findings of this study related to the Gleason score show similarity compared to the previous studies. Besides, a study showed that most of the patients had Gleason score 5-6. ${ }^{19}$ It showed that most of adenocarcinoma prostates occured when the score is moderate differentiated and poorly differentiated. The study showed that adnocarcinoma prostate usually had no symptom meaning that patients did not realize suffering from adenocarcinoma. Meanwhile, the increase of the PSA level can be caused by hiperplasia prostate, inflammation or cancer in prostate, thus, the PSA level needs to be combined with rectal tusae which in adenocarcinoma usually has nodules in the prostate. Furthermore, the serum PSA levels, the Gleason score, and clinical stage have been shown to be useful in the preoperative prediction of final pathological stage. However, in the middle ranges of a given index, these indices lose predictive power. Therefore, additional individual predicting methods are needed, such as molecular markers. ${ }^{20}$

The cav-1 is a major structural coat protein of caveolae, specialized plasma membrane invaginations involved in multiple cellular functions including molecular transport, cell adhesion, and signal transduction. In clinically localized prostate cancer, the cav- 1 is focally expressed by malignant epithelial cells. The cav-1 expression proportionally increases in high-grade primary tumors with lymph node metastases and in metastatic lymph nodes. ${ }^{18}$ Univariate Cox proportional hazards analysis demonstrated that positive cav-1 expression was predictive of a shorter time to disease progression after the radical prostatectomy. The mechanism for increased expression of cav-1 in aggressive prostate cancer remains unclear, however, when compared with serum PSA, serum cav-1 more specifically identifies clinically aggressive disease. This likely reflects the fact that, unlike PSA, cav-1 biologically contributes to malignant progression and the development of castrate-resistance. For the same reason, serum cav-1 measurement may also prove useful as a biomarker in other prostate cancer disease states. Eventhough, there is significantly result between cav-1 and the Gleason score. Obviously, there is no correlation between the serum cav-1 levels with the Gleason score using the Spearman correlation. This might be due to the lack of data.

In conclusion, the positive cav- 1 expression is related to the clinical markers of the disease progression and is also predictive of a poor clinical outcome after the surgery. Therefore, there is no correlation between the PSA and the Gleason score with cav-1 for diagnose of adenocarcinoma prostate. It means that we cannot predict the Gleason score and PSA score only with cav-1. Due to those different markers advantages and disadvantages in predicting the carcinoma prostate, therefore, it need a further study.

\section{References}

1. Li J, Djenaba JA, Soman A, Rim SH, Viraj A, Master. Recent trends in prostate cancer incidence by age, cancer stage, and grade, the United States, 2001-2007. Prostate Cancer. 2012 [cited 2014 Nov 3]:[about 8 p.]. Available from: http://www.hindawi.com/journals/ pc/2012/691380/.

2. Eeles R, Goh C, Castro E, Bancroft E, Guy M, Olama AAA, et al. The genetic epidemiology of prostate cancer and its clinical implication. Nat Rev Urol. 2014;11(1):18-31.

3. Miah S, Catto J. BPH and Prostate cancer risk. Indian J Urol. 2014;30(2):214-8.

4. Beauchamp RD, Evers BM, Mattox KL. Sabiston Textbook of surgery the biological basis of modern surgical practice, $18^{\text {th }}$ ed. Philadelphia: Saunders Elsevier; 2008. p. 2277-80.

5. O'Leary JP. The physiologic basis of surgery. $4^{\text {th }}$ ed. Philadelphia: Lippincott Williams \& Wilkins; 2008. p. 669-70.

6. Vickers. AJ, Brewster SF. PSA Velocity and doubling time in diagnosis and prognosis of prostate cancer. Br J Med Surg Urol. 2012;5(4): 162-8.

7. Gupta A, Gupta D, Raizada A, Gupta NP, Yadav $\mathrm{R}$, Vinayak K, Tewari V. OA hospital based 
study on reference range of serum prostate specific antigen levels. Indian J Med Res. 2014;140(4):507-12.

8. Pakasi RDN. Total prostate specific antigen, prostate specific antigen density and histopatologic analisis on benign enlargement of prostate. IJMS. 2009;5(1):263-74.

9. Heijnsdijk EAM, Wever EM, Auvinen A, Hugosson J, Ciatto S, Nelen V, et al. Quality of life effect of prostate specific antigen screening. N Engl J Med. 2012; 367(7):595-605.

10. Khani F1, Epstein JI. Prostate biopsy specimens with Gleason 3+3=6 and intraductal carcinoma: radical prostatectomy findings and clinical outcomes. Am J Surg Pathol. 2015 Oct;39(10):1383-9.

11. Ko K, Jeong IG, Choi WS, Lim JH, Suh JH, Ku $\mathrm{JH}$, et al. Effect of Gleason scores of lymph node metastases on prognosis of patients with prostate cancer. Int J Clin Exp Pathol. 2014;7(9):6141-8.

12. Yang G, Truong LD, Wheeler TM, Thompson TC. Caveolin-1 expression in clinically confined human prostate cancer: a novel prognostic marker. Cancer Res. 1999;59(22):5719-23.

13. Endi P, Soeharto W. Penanganan Karsinoma Prostat di RSUD Dr. Moewardi Surakarta Januari 2000- Desember 2006. Surakarta 2006

14. Hennis AJ, Hambleton IR, Wu SY, Skeete DH, Nemesure B, Leske MC. Prostate cancer incidence and mortality in barbados, west indies. Prostate Cancer. 2011 [cited 2014 Nov 3]:[about 10 p.]. Available from: http://www. ncbi.nlm.nih.gov/pmc/articles/PMC3200283/.

15. Egawa S, Suyama K, Ohori M, et al. Early detection of prostate cancer. Results of a prostate specific antigen-based detection program in Japan. Cancer. 1995;76(5):463-72.

16. Fall $\mathrm{K}$, Garmo $\mathrm{H}$, Andren $\mathrm{O}$, Axelson $\mathrm{AB}$, Adolfsson J, Adami HO, et al. Prostate Specific Antigen Levels as a Predictor of Lethal Prostate Cancer. J Natl Cancer Inst. 2007;99(7):526-32.

17. Hankey BF, Feuer EJ, Clegg LX, Hayes RB, Legler JM, Prorok PC, et al. Cancer surveillance series: interpreting trends in prostate cancer part I: evidence of the effects of screening in recent prostate cancer incidence, mortality, and survival rates. J Natl Cancer Inst.1999;91(12):1017-24.

18. Corn PG, Thompson TC. Identification of a novel prostate cancer biomarker, caveolin-1: Implications and potential clinical benefit. Cancer Management and Research. 2010;2:(1)111-22.

19. Stark JR, Perner S, Stampfer MJ, Sinnott JA, Finn S, Einsenstein AS, et al. Gleason Score and Lethal Prostate Cancer: Does $3+4=4+3$ ? JCO. 2009; 27(21):3459-64.

20. Lowrance WT, Scardino PT. Predictive Models for Newly Diagnosed Prostate Cancer Patients. Rev Urol. 2009; 11(3): 117-26. 